The Cryosphere Discuss., 4, 2587-2592, 2010

www.the-cryosphere-discuss.net/4/2587/2010/

doi:10.5194/tcd-4-2587-2010

(c) Author(s) 2010. CC Attribution 3.0 License.

\title{
Reply to the comment of Leclercq et al. on "100-year mass changes in the Swiss Alps linked to the Atlantic Multidecadal Oscillation"
}

\author{
M. Huss ${ }^{1}$, R. Hock ${ }^{2}$, A. Bauder ${ }^{3}$, and M. Funk ${ }^{3}$ \\ ${ }^{1}$ Department of Geosciences, University of Fribourg, 1700 Fribourg, Switzerland \\ ${ }^{2}$ Geophysical Institute, University of Alaska Fairbanks, Fairbanks, AK 99775-7320, USA \\ ${ }^{3}$ Laboratory of Hydraulics, Hydrology and Glaciology (VAW), ETH Zürich, 8092 Zürich, \\ Switzerland
}

Received: 26 November 2010 - Accepted: 3 December 2010 - Published: 20 December 2010

Correspondence to: M. Huss (matthias.huss@unifr.ch)

Published by Copernicus Publications on behalf of the European Geosciences Union.
Conventional versus reference-surface mass balance

M. Huss et al.

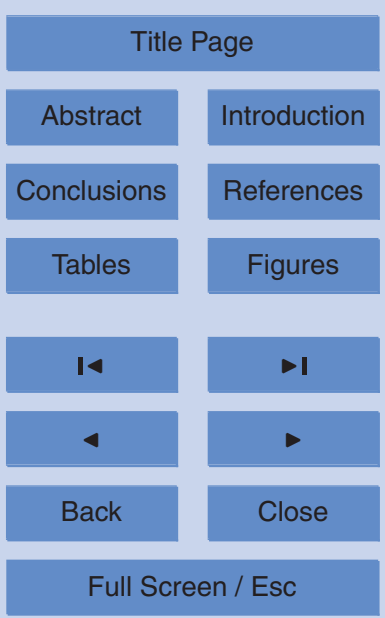

Printer-friendly Version

Interactive Discussion 


\section{Abstract}

In their comment, Leclercq et al. argue that Huss et al. (2010) overestimate the effect of the Atlantic Multidecadal Oscillation (AMO) on the 100-year mass balance variations in the Swiss Alps because time series of conventional balances instead of reference-

5 surface balances were used. Applying the same model as in Huss et al. we calculate time series of reference-surface mass balance, and show that the difference between conventional and reference-surface mass balance is significantly smaller than stated in the comment. Both series exhibit very similar multidecadal variations. The opposing effects of retreat and surface lowering on mass balance partly cancel each other.

\section{Introduction}

Leclercq et al. (2010) question the suitability of conventional mass balance series for climatic interpretation. These balances are computed over the concurrent extent and topography of the glacier, and hence represent the actual mass change. Conventional balances are not directly correlated to variations in climate because they incorporate both climate forcing and changes in glacier hypsometry. For investigating glacier-climate linkages Elsberg et al. (2001) introduced the reference-surface balance defined as the mass balance a glacier would have if its surface geometry is fixed in time.

Based on glacier length change data and a simplified model, Leclercq et al. (2010) compute the present day mean mass balance given that the glaciers had the same size as around 1900. They find the balance of the last decade to be $0.36 \mathrm{~m}$ w.e. $\mathrm{a}^{-1}$ more negative than reported in Huss et al. (2010) and conclude that the relative strength of the Atlantic Multidecadal Oscillation (AMO) signal in the multidecadal variations in Swiss glacier mass loss is overestimated by $50 \%$.

25 We agree with Leclercq et al. (2010) that reference-surface balances are the more relevant quantity for interpreting glacier-climate relations than conventional balances.

\section{Conventional versus reference-surface mass balance}

M. Huss et al.

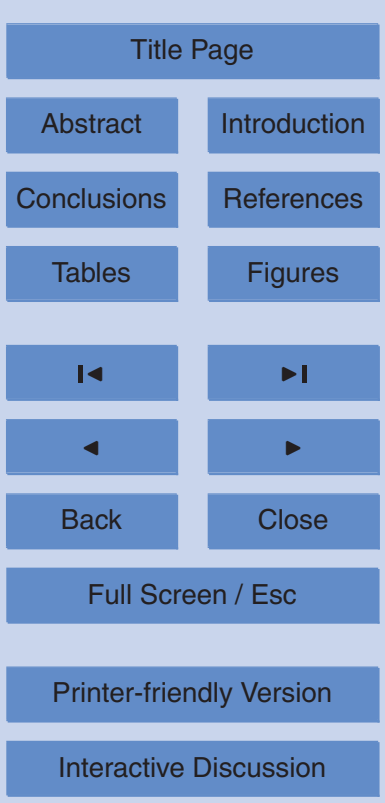


The authors correctly point out that, as the glacier retreats, loss of area at predominantly lower elevations will make the area-averaged mass balance less negative. Thus, the glacier may approach an equilibrium with time even if climate conditions are not becoming more favourable (see Leclercq's Fig. 1). However, their schematic analysis

5 neglects the effect of glacier thinning with mass loss. With decreasing surface elevation, the glacier is exposed to higher air temperatures, resulting in more negative mass balances. The net effect will depend on a number of factors related to climate and glacier geometry (see Supplement Fig. S1).

Here, we redo the analysis by Huss et al. (2010) using reference-surface balances, 10 and find that Leclercq et al. (2010) significantly overestimate the differences between the conventional and the reference-surface mass balance. Based on detailed modelling of the same 30 Swiss glaciers presented in Huss et al. (2010) we show that the conventional mass balance series differ relatively little from reference-surface balances.

\section{Reference-surface balances}

15 For all 30 glaciers we evaluate reference-surface mass balance series for two glacier geometries: the first available Digital Elevation Model (DEM) around 1930 and the last DEM. The mass balance model was calibrated on ice volume changes and in-situ measurements using annually updated glacier extent and surface elevation (Huss et al., 2010). Here, the model was rerun with the same climatic forcing over the 100-year 20 period but without changing the glacier geometry. This allows a consistent comparison of conventional and reference-surface mass balance series.

The differences between 30-glacier averages of the conventional and the referencesurface annual mass balance derived from the glacier hypsometry of the first DEM gradually increase from zero to $0.14 \mathrm{~m}$ w.e. $\mathrm{a}^{-1}$ (last decade's mean) over the 100-year period (Fig. 1). This corresponds to the fraction of mass balance due to the geometric adjustment of the glacier rather than climate change, and is less than $40 \%$ of the value found by Leclercq et al. (2010). We explain the relatively small differences,

\section{Conventional versus reference-surface mass balance}

M. Huss et al.

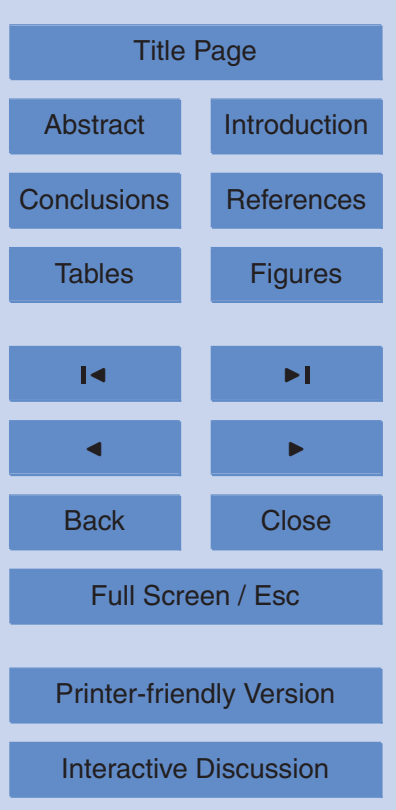


despite substantial overall mass loss, with the compensating effects of surface lowering and glacier terminus retreat (Figs. S1 and S2, online text). The estimate by Leclercq et al. (2010) only accounts for the latter. We find that roughly half of the terminus retreat effect is compensated by glacier thinning (Supplement Table S1). The

5 amplitudes of sinusoidal fits to the multidecadal variations in the reference-surface and the conventional mass balance series are almost identical (Fig. S3). Hence, the contribution of the AMO to mass loss of the Swiss glaciers based on reference-surface balance is only slightly less (41\%) than the 50\% reported in Huss et al. (2010) based on conventional balances. We agree with Leclercq et al. (2010) that the main driver 10 for the glacier retreat since the end of the Little Ice Age is the general warming trend. However, natural multidecadal variations superimposed on this trend lead to periodic phases of more positive or negative mass balances than the overall trend would suggest.

\section{Conclusions}

15 Although reference-surface mass balances are in principal better suited for climatic interpretations (Harrison et al., 2009), practical issues often hamper the applicability of this concept. Errors are involved when extrapolating measured point balances to the hypsometry and extent of the reference surface. When modelling reference-surface balances, results can not be validated against field observations as these refer to another glacier geometry. Thus, the calculation of the reference-surface balance is prone to uncertainties that puts limits on the significance of any derived climatic interpretations.

Our evaluation shows that multidecadal variations in conventional mass balance calculated over the evolving concurrent glacier geometry, and reference-surface balance are similar. Thus, the relative strength of the AMO signal identified in Huss et al. (2010) is only slightly lower when reference-surface instead of conventional balances are used. For the case of last century's glacier mass loss in the Swiss Alps, the opposing

\section{Conventional versus reference-surface mass balance}

M. Huss et al.

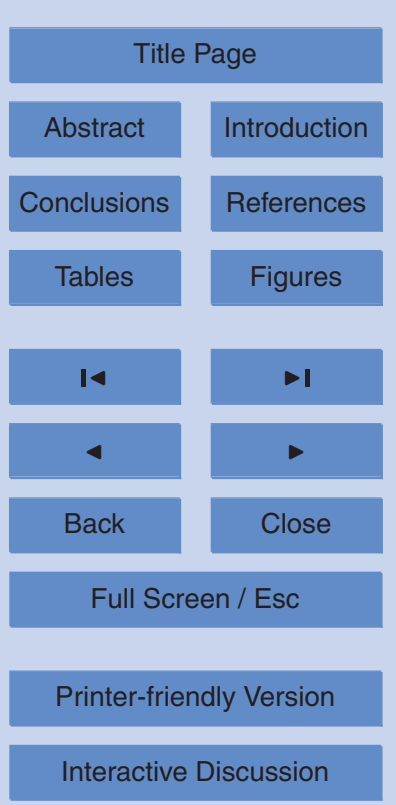


effects of glacier retreat and surface lowering combine to yield little difference between conventional and reference-surface balances. However, we caution against generalizing these results for different glaciers and time periods (see online text).

\section{Supplementary material related to this article is available online at:}

5 http://www.the-cryosphere-discuss.net/4/2587/2010/tcd-4-2587-2010-supplement. pdf.

\section{References}

Elsberg, D. H., Harrison, W. D., Echelmeyer, K. A., and Krimmel, R. M.: Quantifying the effects of climate and surface change on glacier mass balance, J. Glaciol., 47, 649-658, 2001. 2588

10 Harrison, W. D., Cox, L. H., Hock, R., March, R. S., and Petit, E. C.: Implications for the dynamic health of a glacier from comparison of conventional and reference-surface balances, Ann. Glaciol., 50, 25-30, 2009. 2590

Huss, M., Hock, R., Bauder, A., and Funk, M.: 100-year mass changes in the Swiss Alps linked to the Atlantic Multidecadal Oscillation, Geophys. Res. Lett., 37, L10501, doi:10.1029/2010GL042616, 2010. 2588, 2589, 2590

Leclercq, P. W., van de Wal, R. S. W., and Oerlemans, J.: Comment on "100-year mass changes in the Swiss Alps linked to the Atlantic Multidecadal Oscillation" by Matthias Huss et al. (2010), The Cryosphere Discuss., 4, 2475-2481, doi:10.5194/tcd-4-2475-2010, 2010. 2588, 2589, 2590

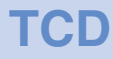

4, 2587-2592, 2010

\section{Conventional versus reference-surface mass balance}

M. Huss et al.

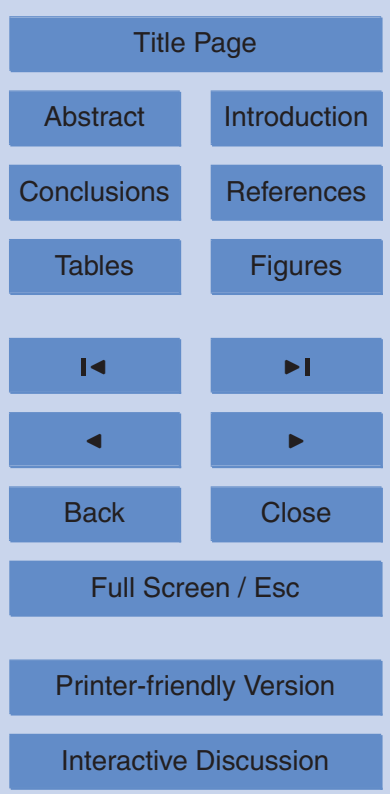




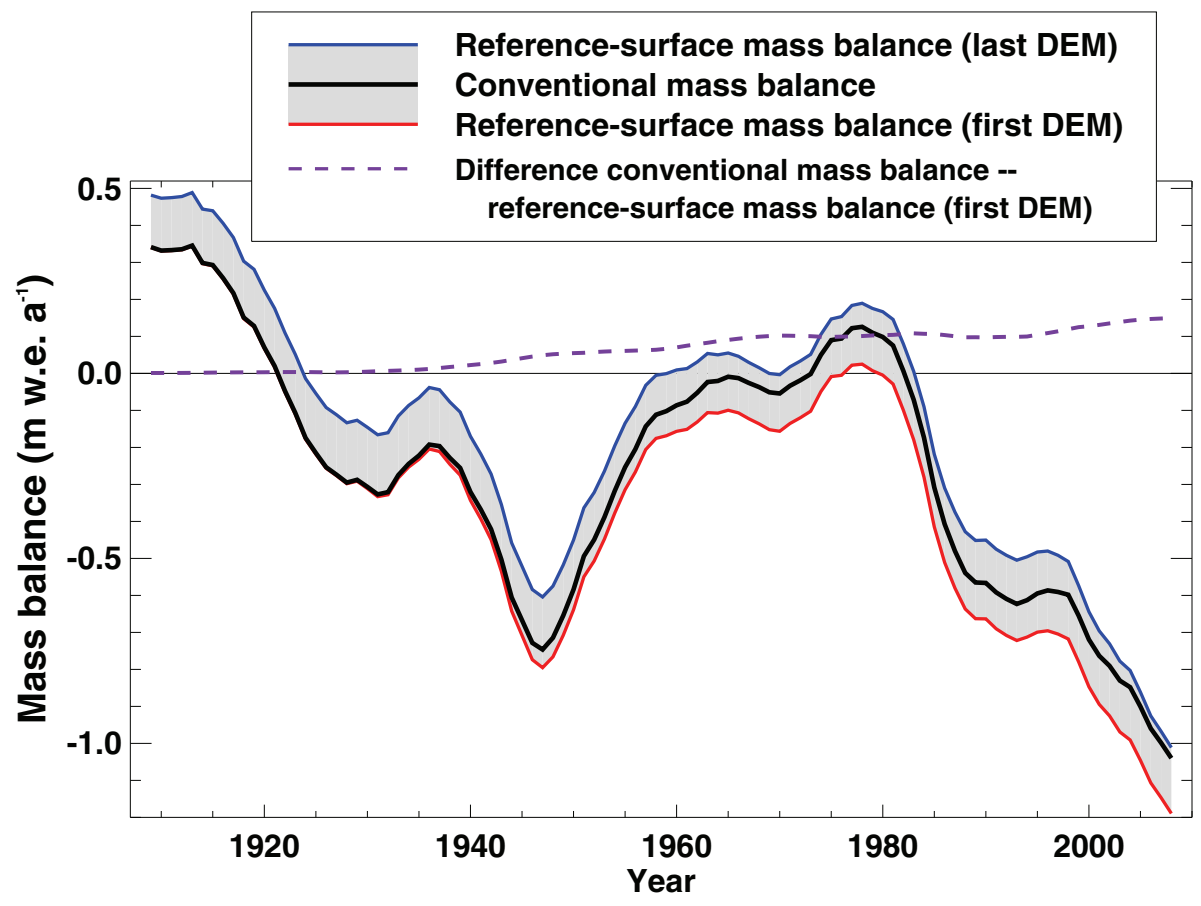

Fig. 1. Comparison of conventional and reference-surface mass balance series over the 20th century. 30-glacier arithmetic averages of annual mass balance are low-pass filtered with an 11 -year running mean. The dashed line refers to the difference between the conventional and the reference-surface (first DEM) mass balance corresponding to the fraction of mass balance caused by geometric adjustment of the glacier rather than climate change.

\section{4, 2587-2592, 2010}

\section{Conventional versus reference-surface mass balance}

M. Huss et al.

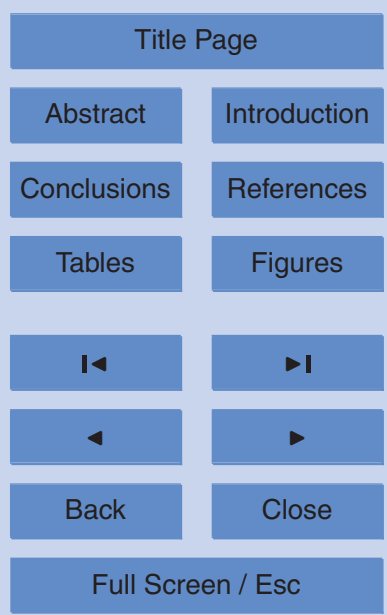

Printer-friendly Version

Interactive Discussion 